\title{
Urologic Chronic Pelvic Pain Syndrome
}

\author{
Viviana Martinez-Bianchi, MD*, Brian H. Halstater, MD
}

\section{KEYWORDS}

- Interstitial cystitis • Bladder pain syndrome • Dysuria

- Urgency • Urologic chronic pelvic pain syndrome

\section{DYSURIA}

Dysuria is urination that is painful or uncomfortable. It is often associated with increased urinary frequency, abnormally frequent urination, or urgency, an abrupt, strong, often overwhelming need to urinate. The most common cause of dysuria is urethral or bladder inflammation, often because of infection. Patients with acute dysuria have symptoms of short duration, usually a few days, often associated with frequency and urgency. Most of these patients have an infection. Table 1 shows the causes of dysuria in four categories: gynecologic, urological, inflammatory, and miscellaneous. Chronic dysuria is defined as pain with urination that has been continuous or recurrent for at least 6 months. It is closely tied to chronic pelvic pain syndrome in women, and prostatodynia (chronic prostate pain) in men. Associated symptoms include allodynia (nonpainful stimuli are perceived as painful) and hyperalgesia (painful stimuli are perceived as more painful than expected). Chronic dysuria is associated with changes in the central nervous system (CNS) that may maintain the perception of pain in the absence of acute injury. ${ }^{1}$ The various causes of chronic dysuria are shown in Table 2.

\section{PAINFUL BLADDER SYNDROME AND INTERSTITIAL CYSTITIS}

Painful bladder syndrome (PBS) is a chronic disease of unknown etiology. PBS presents with chronic pelvic pain, nocturia, increased urinary frequency, and urgency. ${ }^{2}$ The International Continence Society (ICS) defines PBS as "the complaint of suprapubic pain related to bladder filling, accompanied by other symptoms such as increased daytime and night-time frequency, in the absence of proven urinary infection or other obvious pathology." 3 The European Society for the Study of Bladder Pain Syndrome/ Interstitial Cystitis calls the disease bladder pain syndrome (BPS), including a history of more than 6 months of pelvic pain, pressure, or discomfort perceived to be related

Duke Family Medicine Residency Program, Division of Family Medicine, Department of Community and Family Medicine, Duke University, DUMC 3886, Durham, NC 27710, USA

* Corresponding author.

E-mail address: marti213@mc.duke.edu 


\begin{tabular}{|ll|}
\hline Table 1 & \\
Acute causes of dysuria & \\
Urologic & Balanitis \\
& Bladder neck obstruction \\
& Carcinoma or carcinoma in situ \\
& Epididymitis/orchitis \\
& Infectious urethritis (common etiologies include Chlamydia, \\
& gonorrhea, ureaplasma urealyticum, Candida, Mycoplasma, \\
& and herpes simplex) \\
& Pyelonephritis \\
& Radiation urethritis \\
& Urethral caruncle \\
& Urethral diverticulum \\
& Urethral stricture \\
& Urethral trauma \\
& Urinary retention \\
& Urinary tract infections \\
& Urolithiasis (in bladder, urethra or lower ureters) \\
\hline Gynecologic & Cancer of the cervix, uterus, and ovaries \\
& Bartholin adenitis or abscess \\
& Cervicitis (similar organisms as infectious urethritis) \\
& Pelvic inflammatory disease \\
& Vulvovaginitis \\
& Urinary retention \\
\hline Psychiatric & Rheumatologic disorders: \\
\hline Drug Side Effects & Spondyloarthropathies, reactive arthritis, Behçet syndrome \\
\hline Miscellaneous & Dermatitis \\
& Contact irritants: contraceptive foams, douches, diaphragm \\
\hline Inflammatory Conditions & Obsessive washing \\
\hline & Amoxicillin, cyclophosphamides, aspirin, nonsteroidal anti- \\
& Foreign bodies in bladder, penis, vagina \\
\hline
\end{tabular}

to the urinary bladder, accompanied by at least one other urinary symptom, such as persistent urge to void or urinary frequency. ${ }^{1}$

One common subset of PBS is interstitial cystitis (IC). IC traditionally is defined as a chronic sterile inflammatory disease of the bladder, with either glomerulations or a classic Hunner ulcer found on cystoscopy. IC is more common in women, with a median age at onset of 40 years. In recent years, the diagnostic approach to IC has become more dependent on symptoms and less reliant on cystoscopic evaluation and biopsy. ${ }^{2-5}$

\section{PROSTATODYNIA}

There appears to be a significant overlap between the symptoms experienced by women diagnosed with PBS (with or without IC) and those of men with chronic prostatitis/chronic pelvic pain syndrome (CPPS). Active trigger points in internal and external pelvic regions that consistently reproduce specific patterns of referred pain in both men with CPPS and women with PBS have been identified. 6,7 Up to $70 \%$ of men with symptoms of nonbacterial prostatitis and prostatodynia have glomerulations and submucosal hemorrhages when undergoing bladder distention under anesthesia, raising the possibility that some cases of prostatitis may actually be IC. ${ }^{8}$ 


\begin{tabular}{|ll|}
\hline Table 2 & \\
Differential diagnosis of chronic & dysuria \\
Urological & Chronic prostatitis/prostate pain syndrome/UCPPS (urologic \\
& chronic pelvic pain syndrome) \\
& Epididymo-orchitis \\
Interstitial cystitis/bladder pain syndrome/UCPPS & Overactive bladder \\
& Postvasectomy pain syndrome \\
& Scrotal pain syndrome \\
& Urethral diverticulum \\
& Urethritis/urethral pain syndrome \\
& Renal cell tumors, bladder, prostate, vagina, vulvar, cervical \\
& and penile cancers \\
\hline Neoplastic & Spondyloarthropathies \\
& Autoimmune disorders \\
\hline Inflammatory Conditions & Atrophic vaginitis \\
\hline Gynecologic & Cancer of the cervix, ovaries, uterus, vagina \\
& Endometriosis \\
& Generalized vaginal pain syndrome \\
& Vulvodynia \\
\hline Anorectal & Proctitis \\
& Anal fissure \\
& Hemorrhoids \\
\hline Neuromuscular & Pudendal neuropathy/pudendal neuralgia \\
& Sacral spinal cord pathology \\
\hline Psychogenic Conditions & Somatization disorder \\
& Major depression \\
& Stress disorders, post-traumatic stress disorder \\
& Anxiety \\
\hline & Cyclophosphamides, aspirin, nonsteroidal anti-inflammatory \\
& agents, allopurinol \\
\hline
\end{tabular}

The National Institute of Diabetes and Digestive and Kidney Diseases (NIDDK) classification of prostatitis has replaced the older terms nonbacterial prostatitis and prostatodynia with category 3 chronic prostatitis/chronic pelvic pain syndrome (CP/CPPS, or simply CPPS). Just as with IC, these patients have pelvic and genital pain, often associated with urinary and sexual symptoms, but no history of documented urinary tract infection (UTI). Given the overlap of symptoms, the NIDDK has proposed that Urologic Chronic Pelvic Pain Syndromes (UCPPS) be used as an umbrella term for CPPS and IC. ${ }^{9}$

\section{PREVALENCE}

The true prevalence of PBS is not known. In a population-based study of patients in primary care, the prevalence of PBS was between $0.45 \%$ and $12.6 \% .{ }^{10} \mathrm{~A}$ population-based study in Finland concluded that IC affects $0.3 \%$ to $0.68 \%$ of women. ${ }^{11}$ Another study in the Pacific Northwest concluded that the prevalence of IC symptoms was between $6.2 \%$ and $11.2 \%$ in women, and $2.3 \%$ and $4.6 \%$ in men. ${ }^{12}$

\section{PATHOPHYSIOLOGY}

PBS appears to have a multifactorial etiology. ${ }^{3}$ Some of the mechanisms cited include: immunologic mechanisms, uroepithelial dysfunction, mast cell activation, and neural 
inflammation. These mechanisms may be associated with the development of myofascial trigger points. Psychological factors can perpetuate these symptoms, with subsequent worsening and establishment of a chronic syndrome. ${ }^{13}$

UTIs may trigger PBS in some patients. In a retrospective study of 314 women with recent-onset PBS, $18 \%$ to $36 \%$ of them had evidence of a UTI at the onset of symptoms. ${ }^{14}$ However, neither bacterial nor viral DNA is found in bladder biopsies of patients with PBS/IC, making chronic infection an unlikely cause for this syndrome. ${ }^{15}$

Some IC patients have increased bladder epithelial permeability, where the bladder glycosaminoglycan layer is damaged or defective, ${ }^{16}$ exposing nerves to irritants within the bladder. Mast cells may be involved in the neurogenic inflammation observed in patients with IC, which leads to urinary frequency and detrusor overactivity. Increases in nerve growth factor have been detected in women with IC and men with prostatitis. ${ }^{17}$

The pain associated with PBS appears to involve an alteration in bladder sensory physiology, such that bladder-afferent neurons respond in an exaggerated manner to normally innocuous stimuli (allodynia). ${ }^{18} \mathrm{~A}$ small study of subjects with IC showed generalized hypersensitivity to deep tissue stimulation with lower thresholds, and tolerance of bladder, muscle, and ischemic stimulation compared with healthy subjects. In the same study, subjects with IC had more catastrophizing, a perception of decreased health, more somatic complaints, and increased vigilance to sensations. ${ }^{19}$

Patients with PBS often have myofascial trigger points, with tension and tenderness of the pelvic floor musculature on physical examination. It is not known, however, whether these musculoskeletal abnormalities are a consequence of the lower urinary tract symptoms, or are a primary disorder that gives rise to secondary urinary symptoms. ${ }^{20}$ Irritable bowel syndrome, IC, and other chronic pelvic pain (CPP) disorders often occur concomitantly, possibly because of neural cross-talk via the convergence of pelvic afferents. ${ }^{21}$ This may occur at the level of the dorsal root ganglia, spinal cord, or brain. ${ }^{22}$

\section{PATIENT PRESENTATION}

A detailed history is extremely important in this clinical syndrome, because multiple etiologies need to be ruled out. Characteristics of the pain, location, radiation, timing, associated voiding symptoms (frequency, urgency), sexual history, sexual functioning, and comorbid conditions need to be discussed in detail with the patient.

In general, PBS patients report pain in the following locations: $83 \%$ suprapubic, $36 \%$ urethral, $21 \%$ genital, and $29 \%$ nongenitourinary. Many patients will report pain that changes locations and occurs in multiple sites. ${ }^{7}$ Irritative voiding symptoms (urgency, increased frequency, nocturia, dysuria) and dyspareunia are common, and $84 \%$ to $90 \%$ of patients with PBS report worsening of pain with bladder filling. ${ }^{3,23}$ Burning and pain during urination occurs in $69 \%$ of patients. Pain may be described as aching, throbbing, tender, and piercing. Most women note that pain is worsened by touching, tampons, and intercourse. Some have worsening with urination or while riding in a car, ${ }^{7}$ and some women report a pain flare at the time of the menstrual cycle. $^{24}$

\section{CLINICAL SYMPTOM SCALES}

Several validated questionnaires are used to distinguish PBS from other urinary tract pathologies, although none is specific enough to be used as the sole diagnostic 
indicator. These tools also can be used to monitor the treatment efficacy of those who have already been diagnosed. ${ }^{25}$

For women, these include

- The O'Leary-Sant IC Symptom Index (ICSI) and IC Problem Index (ICPI) measure urinary and pain symptoms and assess how problematic symptoms are for patients with IC. ${ }^{26}$

- The Pain, Urgency, Frequency Symptom Scale (PUF, Fig. 1) collects symptoms and bother information in women. A PUF score of 13 or greater should prompt the physician to further evaluate the patient for IC. ${ }^{27}$

\section{PELVIC PAIN and URGENCY/FREQUENCY PATIENT SYMPTOM SCALE}

Please circle the answer that best describes how you feel for each question.

\begin{tabular}{|c|c|}
\hline 1 & $\begin{array}{l}\text { How many times do you go to the } \\
\text { bathroom during the day? }\end{array}$ \\
\hline \multirow[t]{2}{*}{2} & $\begin{array}{l}\text { a. How many times do you go to } \\
\text { the bathroom at night? }\end{array}$ \\
\hline & $\begin{array}{l}\text { b. If you get up at night to go to } \\
\text { the bathroom, does it bother you? }\end{array}$ \\
\hline \multirow[t]{2}{*}{3} & $\begin{array}{l}\text { a. Do you now or have you ever } \\
\text { had pain or symptoms during } \\
\text { or after sexual intercourse? }\end{array}$ \\
\hline & $\begin{array}{l}\text { b. Has pain or urgency ever made } \\
\text { you avoid sexual intercourse? }\end{array}$ \\
\hline 4 & $\begin{array}{l}\text { Do you have pain associated with } \\
\text { your bladder or in your pelvis } \\
\text { (vagina, labia, lower abdomen, } \\
\text { urethra, perineum, testes, or } \\
\text { scrotum)? }\end{array}$ \\
\hline \multirow[t]{2}{*}{5} & a. If you have pain, is it usually \\
\hline & b. Does your pain bother you? \\
\hline 6 & $\begin{array}{l}\text { Do you still have urgency after } \\
\text { going to the bathroom? }\end{array}$ \\
\hline \multirow[t]{2}{*}{7} & a. If you have urgency, is it usually \\
\hline & b. Does your urgency bother you? \\
\hline 8 & $\begin{array}{c}\text { Are you sexually active? } \\
\text { Yes__ No }\end{array}$ \\
\hline
\end{tabular}

\begin{tabular}{|c|c|c|c|c|c|c|}
\hline 0 & 1 & 2 & 3 & 4 & $\begin{array}{l}\text { SYMPTOM } \\
\text { SCORE }\end{array}$ & $\begin{array}{l}\text { BOTHER } \\
\text { SCORE }\end{array}$ \\
\hline $3-6$ & $7-10$ & $11-14$ & $15-19$ & $20+$ & & \\
\hline 0 & 1 & 2 & 3 & $4+$ & & \\
\hline $\begin{array}{l}\text { Never } \\
\text { Bothers }\end{array}$ & Occasionally & Usually & Always & & & \\
\hline Never & Occasionally & Usually & Always & & & \\
\hline Never & Occasionally & Usually & Always & & & \\
\hline \multirow[t]{2}{*}{ Never } & Occasionally & Usually & Always & & & \\
\hline & Mild & Moderate & Severe & & & \\
\hline Never & Occasionally & Usually & Always & & & \\
\hline \multirow[t]{2}{*}{ Never } & Occasionally & Usually & Always & & & \\
\hline & Mild & Moderate & Severe & & & \\
\hline Never & Occasionally & Usually & Always & & & \\
\hline & & & & & & \\
\hline
\end{tabular}

\begin{tabular}{|r|r|}
\hline $\begin{array}{r}\text { SYMPTOM SCORE }= \\
(1,2 \mathrm{a}, 3 \mathrm{a}, 4,5 \mathrm{a}, 6,7 \mathrm{a})\end{array}$ & \\
\hline $\begin{array}{r}\text { BOTHER SCORE }= \\
(2 \mathrm{~b}, 3 \mathrm{~b}, 5 \mathrm{~b}, 7 \mathrm{~b})\end{array}$ & \\
\hline TOTAL SCORE (Symptom Score + Bother Score) $=$ & \\
\hline
\end{tabular}

2000 C. Lowell Parsons, M.D

Total score ranges from 1 to 35 .

A total score of $10-14=74 \%$ likelihood of positive PST; $15-19=76 \% ; 20$ or above $=91 \%$ likelihood of positive PST.

Revised 11/17/2003 (C) 2000 C. Lowell Parsons, M.D. Reprinted with permission.

Fig. 1. Pelvic pain and urgency/frequency patient symptom scale. (Courtesy of C. Lowell Parsons, MD; with permission.) 


\section{For men, these include}

- The National Institutes of Health (NIH) Chronic Prostatitis Symptom Index (CPSI), which allows quantification of the pain, voiding symptoms, and quality of life in men (Fig. 2). ${ }^{28}$

\section{NIH-Chronic Prostatitis Symptom Index (NIH-CPSI)}

\begin{tabular}{|c|c|c|c|}
\hline \multicolumn{4}{|c|}{$\begin{array}{l}\text { Pain or Discomfort } \\
\text { In the last week, have you experienced any pain or } \\
\text { discomfort in the following areas? }\end{array}$} \\
\hline \multicolumn{4}{|c|}{$\begin{array}{l}\text { a. Area between rectum and } \\
\text { testicles (perineum) }\end{array}$} \\
\hline b. & Testicles & $\square_{1}$ & $\square_{0}$ \\
\hline c. & $\begin{array}{l}\text { Tip of the penis (not related to } \\
\text { urination) }\end{array}$ & $\square_{1}$ & $\square_{0}$ \\
\hline d. & $\begin{array}{l}\text { Below your waist, in your } \\
\text { pubic or bladder area }\end{array}$ & $\square_{1}$ & $\square_{0}$ \\
\hline
\end{tabular}

2. In the last week, have you experienced:

6. How often have you had to urinate again less than two hours after you finished urinating, over the last week?

$\square_{0}$ Not at all

$\square_{1}$ Less than 1 time in 5

$\square_{2}$ Less than half the time

$\square_{3}$ About half the time

$\square_{4}$ More than half the time

$\square_{5}$ Almost always

Impact of Symptoms

7. How much have your symptoms kept you from doing the kinds of things you would usually do, over the last week?

$\square_{0}$ None

$\square_{1}$ Only a little

$\square_{2}$ Some

a. Pain or burning during Yes No urination?

$\square_{3} \mathrm{Alot}$

b. Pain or discomfort during or after sexual climax (ejaculation)?

8. How much did you think about your symptoms, over the last week?

$\square_{0}$ None

$\square_{1}$ Only a little

$\square_{2}$ Some

$\square_{3}$ A lot
$\square_{0}$ Never
$\square_{1}$ Rarely
$\square_{2}$ Sometimes
$\square_{3}$ Often
$\square_{4}$ Usually
$\square_{5}$ Always

4. Which number best describes your AVERAGE pain or discomfort on the days that you had it, over the last week?

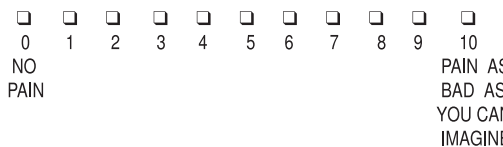

Quality of Life

9. If you were to spend the rest of your life with your symptoms just the way they have been during the last week, how would you feel about that?

$\square_{0}$ Delighted

$\square_{1}$ Pleased

$\square_{2}$ Mostly satisfied

$\square_{3}$ Mixed (about equally satisfied and dissatisfied)

$\square_{4}$ Mostly dissatisfied

$\square_{5}$ Unhappy

$\square_{6}$ Terrible

Urination

5. How often have you had a sensation of not emptying your bladder completely after you finished urinating, over the last week?
$\square_{0}$ Not at all
$\square_{1}$ Less than 1 time in 5
$\square_{2}$ Less than half the time
$\square_{3}$ About half the time
$\square_{4}$ More than half the time
$\square_{5}$ Almost always

Fig. 2. NIH-Chronic Prostatitis Symptom Index (NIH-CPSI). (From Litwin MS, McNaughtonCollins M, Fowler FJ Jr, et al. The National Institutes of Health chronic prostatitis symptom index: development and validation of a new outcome measure. J Urol 1999;162:369-75.) 


\section{PAST MEDICAL HISTORY}

The past medical history should be obtained, including the following: ${ }^{13,29}$

- UTI history

- Sexually transmitted disease (STD) history

- History of bladder problems or known urological diseases

- Voiding dysfunction in childhood, including enuresis, urgency, increased frequency, or recurrent UTIs

- Sexual history

- Previous pelvic surgery or radiation

- Presence of allergies (systemic or dermatologic)

- Presence of autoimmune diseases

- History of cardiovascular conditions

- History of neurologic conditions

- Concomitant chronic syndromes (irritable bowel syndrome, fibromyalgia, migraine headaches, vulvodynia, chronic fatigue syndrome, low back pain)

- Psychiatric history, including depression, anxiety, obsessive-compulsive disorder, maladaptive coping, and social support.

\section{RISK ASSESSMENT}

Women tend to have a higher risk of PBS than men, with a female-to-male risk ratio of approximately $9: 1 .^{30}$ Several recent studies and reviews have looked at the correlation between PBS and other chronic conditions. In a study published in 2009 by Warren and colleagues, 11 antecedent syndromes were diagnosed more often in those with PBS, the most common being fibromyalgia-chronic widespread pain, chronic fatigue syndrome, sicca syndrome, and irritable bowel syndrome. Other less commonly associated syndromes include migraine headaches, depression, and allergies. ${ }^{31}$ Several studies have reported an association between IC and sexual, physical, and emotional abuse. $^{32}$

Familial occurrence of PBS is suggested by a study that found that adult female first-degree relatives of patients with IC may have a prevalence of IC 17 times that found in the general population. A greater concordance of IC among monozygotic than dizygotic twins also has been described. ${ }^{3}$ Another group of researchers found an autosomal-dominant link in a cohort of families. ${ }^{33}$

\section{SEXUAL FACTORS}

Vulvodynia and dyspareunia are common among women with PBS. ${ }^{34}$ Anticipation of pain with intercourse causes anxiety, and patients may try to avoid intimacy, putting strain on their romantic relationships. Depression also can occur as a result of the chronic pain, the impact the pain is having on the patient's life, or from shame and guilt due to current or past sexual experiences. There can be a connection with posttraumatic stress disorder (PTSD), leading to avoidance, hyperarousal, or reexperiencing difficult past encounters. ${ }^{35}$ In a study of 122 vulvodynia patients, most (84\%) had a positive Potassium Sensitivity Test, and $80 \%$ had urgency or increased frequency, leading the authors to conclude that the etiology of the patients' pain was in the bladder (IC), and that vulvodynia in many patients was likely referred pain from the urinary bladder. ${ }^{36}$ 
In obtaining a sexual history, questions should be clear and direct: ${ }^{37,38}$

- Many people with IC or painful bladder syndrome experience difficulty with sexual functioning. Is this a problem for you?

- Does the sexual problem happen all the time?

- How long have you had the sexual problem?

- Does the problem occur with masturbation?

- Do you have problems when your partner attempts penetration?

- Does the problem happen with specific activities?

- How does the problem affect your relationship?

- Could you point out where it hurts on this diagram of the genitalia?

- How does this sexual problem affect you?

- How is your partner affected by the sexual problem?

- Does the sexual problem cause you to withdraw from your partner?

- Does the problem cause you to refrain from sexual activity, including masturbation?

- What tests have you already had in the evaluation of your sexual health concern?

- What treatments have you already received, and what are the outcomes of the various treatments?

\section{NUTRITION}

PBS symptoms are influenced by food and beverages in $90 \%$ of patients. The most frequently reported bothersome items were caffeinated drinks, tea, carbonated and alcoholic beverages, fruits (tomatoes, grapefruit, lemons, oranges, pineapple) and juices (grapefruit, cranberry, orange, pineapple), artificial sweeteners, and spicy foods containing tomato products or hot pepper. Three quarters of patients in one study reported that larger meals caused more bladder symptoms than smaller meals. Some had symptom relief following the ingestion of alkalizing agents, such as calcium glycerophosphate (Prelief) or sodium bicarbonate (baking soda). ${ }^{39}$

\section{MENTAL HEALTH}

Depression and panic disorder are significantly more common in men and women with pelvic pain conditions. Patients with PBS also report worse quality of life in regard to mental health. They report significant sleep dysfunction, depression, anxiety, and stress compared with asymptomatic controls. Patients with PBS do more catastrophic thinking, have greater sexual dysfunction, and perceive lower social support than controls. These levels of stress and anxiety appear related to patient symptom severity. ${ }^{40,41}$ Helpful questionnaires ${ }^{42}$ include the Patient Health Questionnaire (PHQ-9) (Fig. 3), ${ }^{43}$ which assesses depression and anxiety, and the Pain Catastrophizing Scale (PCS), ${ }^{44}$ which measures negative thoughts associated with pain.

\section{PHYSICAL EXAMINATION}

The physical examination should include:

- Abdominal examination for scars, hernias, areas of tenderness, masses, or organomegaly 
PATIENT HEALTH QUESTIONNAIRE (PHQ-9)

NAME:

DATE:

Over the last 2 weeks, how often have you been bothered by any of the following problems? (use " $\checkmark$ " to indicate your answer)

1. Little interest or pleasure in doing things

2. Feeling down, depressed, or hopeless

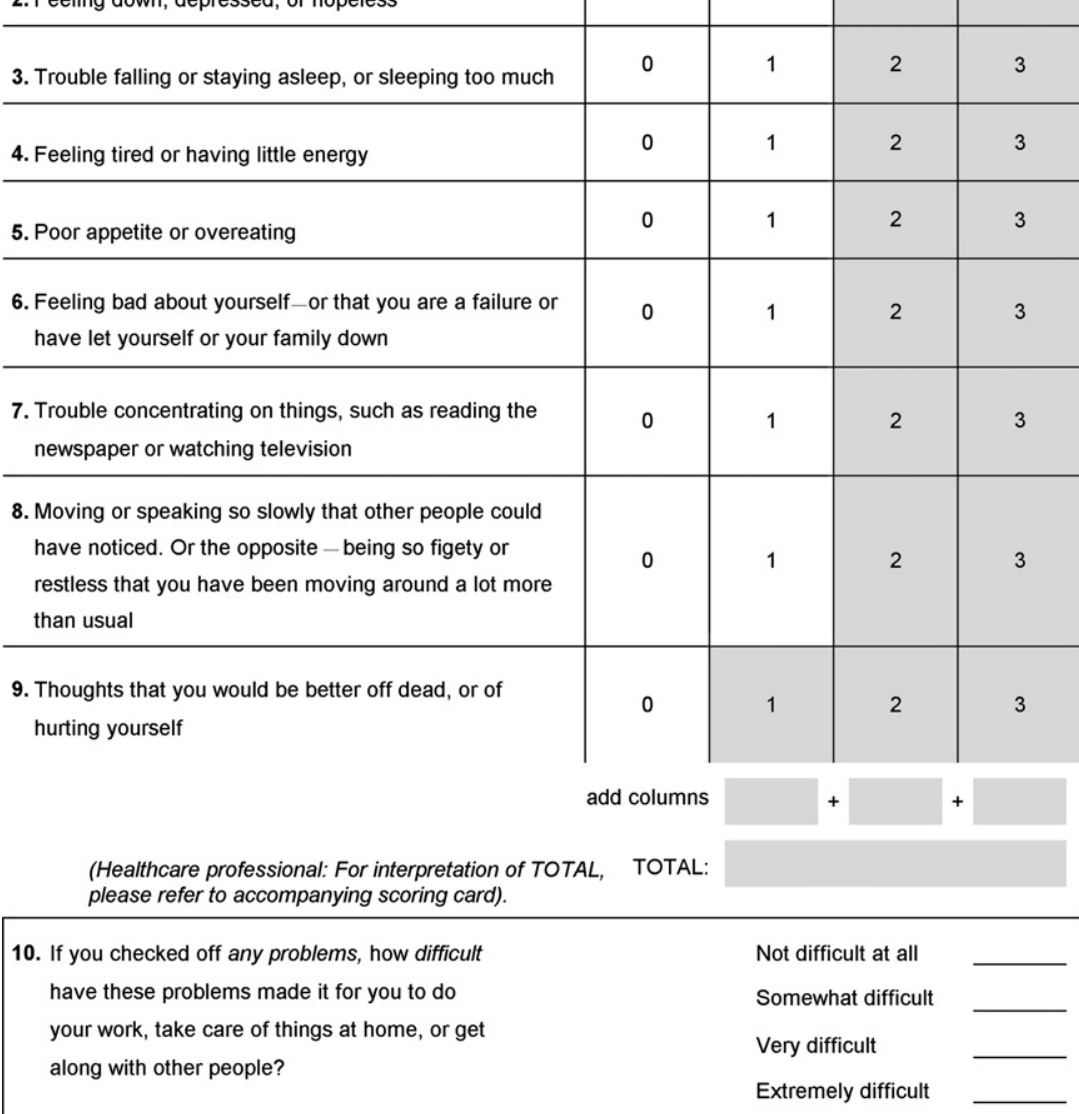

Copyright $\odot 1999$ Pfizer Inc. All rights reserved. Reproduced with permission. PRIME-MD $\odot$ is a trademark of Pfizer Inc. A2663B 10-04-2005

Fig. 3. Patient Health Questionnaire (PHQ-9). (Courtesy of Pfizer, Inc, New York, New York. Copyright (c) Pfizer, Inc.; all rights reserved.)

- Musculoskeletal examination for kyphosis and abduction and adduction of the hips

- Skin examination for rashes or lesions

- Neurologic examination for motor strength and areas of increased or decreased sensation. 


\section{PHQ-9 Patient Depression Questionnaire}

For initial diagnosis:

1. Patient completes PHQ-9 Quick Depression Assessment.

2. If there are at least $4 \checkmark \mathrm{s}$ in the shaded section (including Questions \#1 and \#2), consider a depressive disorder. Add score to determine severity.

\section{Consider Major Depressive Disorder}

- if there are at least $5 \checkmark \mathrm{s}$ in the shaded section (one of which corresponds to Question \#1 or \#2)

\section{Consider Other Depressive Disorder}

- if there are 2-4 $\checkmark \mathrm{s}$ in the shaded section (one of which corresponds to Question \#1 or \#2)

Note: Since the questionnaire relies on patient self-report, all responses should be verified by the clinician, and a definitive diagnosis is made on clinical grounds taking into account how well the patient understood the questionnaire, as well as other relevant information from the patient.

Diagnoses of Major Depressive Disorder or Other Depressive Disorder also require impairment of social, occupational, or other important areas of functioning (Question \#10) and ruling out normal bereavement, a history of a Manic Episode (Bipolar Disorder), and a physical disorder, medication, or other drug as the biological cause of the depressive symptoms.

To monitor severity over time for newly diagnosed patients or patients in current treatment for depression:

1. Patients may complete questionnaires at baseline and at regular intervals (eg, every 2 weeks) at home and bring them in at their next appointment for scoring or they may complete the questionnaire during each scheduled appointment.

2. Add up $\checkmark \mathrm{s}$ by column. For every $\checkmark$ : Several days $=1$ More than half the days $=2$ Nearly every day $=3$

3. Add together column scores to get a TOTAL score.

4. Refer to the accompanying PHQ-9 Scoring Box to interpret the TOTAL score.

5. Results may be included in patient files to assist you in setting up a treatment goal, determining degree of response, as well as guiding treatment intervention.

Scoring: add up all checked boxes on PHQ-9

For every $\checkmark$ Not at all $=0$; Several days $=1$;

More than half the days $=2 ;$ Nearly every day $=3$

Interpretation of Total Score

\begin{tabular}{|c|l|}
\hline Total Score & \multicolumn{1}{|c|}{ Depression Severity } \\
\hline $1-4$ & Minimal depression \\
\hline $5-9$ & Mild depression \\
\hline $10-14$ & Moderate depression \\
\hline $15-19$ & Moderately severe depression \\
\hline $20-27$ & Severe depression \\
\hline
\end{tabular}

PHQ9 Copyright $\left(\mathcal{C}\right.$ Pfizer Inc. All rights reserved. Reproduced with permission. PRIME-MD ${ }^{\circledR}$ is a trademark of Pfizer Inc.

A2662B 10-04-2005

Fig. 3. (continued)

Pelvic examination in women needs to be detailed, mapping areas of tenderness and grading the degree of tenderness: ${ }^{29}$

- Inspect vulva and introitus for areas of irritation, ulceration, desquamation, and signs of endometriosis or herpes.

- Palpate for tenderness of vestibular glands or vulvar skin.

- Look for vaginal spasms or tenderness during insertion and opening of speculum. Inspect for vaginal discharge, vaginal wall irritation. Check vaginal fornices for endometriosis.

- Inspect cervix for ulcerations or discharge. 
- Do bimanual examination and palpate the whole pelvic floor musculature. Evaluate for tightness, tenderness, taut bands, or pain radiation that duplicates symptoms, particularly in the muscles and connective tissue lateral to the urethra. $^{45}$

Genitourinary examination in men also needs to be detailed and may include a pelvic examination in lithotomy position:

- Inspect for lesions, asymmetry, and skin changes.

- Do a digital rectal examination (DRE) to evaluate for prostate changes and tenderness of prostate or anorectal area. Examine the muscles lateral to the prostate and in the urogenital diaphragm. Palpate for trigger points in the perineal body. ${ }^{45}$ Palpate for tenderness of the bladder, prostate, levator, and adductor muscles of the pelvic floor.

- Palpate scrotal contents for tenderness or masses in the testis or epididymus.

- Inspect penis for meatal discharge, penile lesions, and balanitis.

- Measure postvoid residual urine with ultrasound. ${ }^{46}$

\section{LABORATORY AND OTHER TESTING Voiding Diary}

Patients should keep a 3-day voiding diary, recording volumes of intake and output, as well as voiding times and sensation at voiding.

\section{Urine Analysis, Culture, Cytology}

- Urinalysis for blood, glucose, nitrites, and leukocyte esterase should be performed. If hematuria is present, further testing may be necessary to exclude other disease processes with which IC can be mistaken, including neoplasia. ${ }^{47}$

- The midstream urine culture for women and the two-glass test for men (urine cultures of initial stream before prostatic massage, and midstream after massage) should be performed to rule out infection. ${ }^{42}$ If sterile pyuria is identified, an acid fast bacilli smear and culture to rule out tuberculosis (TB) should be performed in high-risk populations.

- Urine cytology is recommended on all patients. In a large study of patients diagnosed with IC, $1 \%$ actually had transitional cell carcinoma. ${ }^{48}$

\section{Cystoscopy}

The role of cystoscopy in diagnosing IC has become controversial. Although PBS is now considered a clinical syndrome, until recently cystoscopy was regarded as an essential diagnostic tool, and cystoscopy and hydrodistension under anesthesia were the gold standards for the diagnosis and initial treatment of IC. ${ }^{3}$ To be diagnosed with IC, patients previously needed to have either glomerulations on cystoscopic examination or classic Hunner ulcer, and either pain associated with the bladder or urinary urgency. Some authors still advocate that a cystoscopic examination for glomerulations should be done after distention of the bladder under anesthesia to 80 to $100 \mathrm{~cm} \mathrm{H} \mathrm{H}_{2} \mathrm{O}$ for 1 to 2 minutes, ${ }^{3}$ looking for glomerulations, suburothelial hemorrhages, or ulceration. Any suspicious lesion should be biopsied. ${ }^{46,47}$ In Europe, biopsy findings that are accepted as positive signs of BPS are inflammatory infiltrates, granulation tissue, detrusor mastocytosis, or intrafascicular fibrosis. ${ }^{49}$ 


\section{Urodynamics}

A full cystometrogram may need to be performed to define the patient's bladder sensation, capacity, and compliance, and to rule out detrusor overactivity, significant hypocompliance, or bladder outlet obstruction. ${ }^{46}$ A small study comparing overactive bladder $(\mathrm{OAB})$ patients with those diagnosed with PBS showed that the urodynamic characteristics of the patients with PBS were significantly different from those of the patients with $\mathrm{OAB}$. The PBS/IC group showed a greater premature filling sensation and decreased bladder capacity compared to the OAB group and were able to handle smaller urine volumes. $70 \%$ patients with $\mathrm{OAB}$ had involuntary detrusor contraction while IDC was not observed in the PBS/IC group. ${ }^{50}$

\section{Potassium Sensitivity Test}

In individuals with a healthy bladder, less than 3\% will experience symptoms of urgency or pain in response to intravesical potassium; when they do, their reactions are mild. However, about $80 \%$ of patients with IC have a positive potassium sensitivity test. Their dysfunctional bladder epithelium allows potassium to diffuse into the bladder muscularis layer, causing an irritating effect that depolarizes nerve and muscle and leads to tissue injury. The potassium sensitivity test is considered positive if the patient assigns a grade of 2 or higher on either the urgency or the pain scales. ${ }^{51}$

\section{TREATMENT}

Only two treatments are currently approved by the US Food and Drug Administration for treating IC: oral pentosan polysulfate and intravesical dimethyl sulfoxide (DMSO), but many other treatments have been used. Treatment for patients with PBS should be addressed individually, based on the patient's most significant symptom(s). Often, patients will need a multisystem, multidisciplinary approach. The mnemonic UPOINT $^{40}$ can be helpful in individualizing therapy:

Urinary symptoms

Psychosocial dysfunction

Organ-specific findings

Infection

Neurologic dysfunction

Tenderness of muscles.

\section{Oral Medications}

1. Amitriptyline 25 to $100 \mathrm{mg}$ by mouth at bedtime appears to be safe and effective in the treatment of IC, resulting in a $64 \%$ response rate ${ }^{52}$ and decreasing pain and urgency intensity. Patients need to be counseled about anticholinergic adverse effects, with mouth dryness being the most common. Dose should be increased gradually, and the lowest effective dose should be used. ${ }^{53}$

2. Pentosan polysulfate sodium (PPS) $300 \mathrm{mg}$ by mouth three times daily has been shown to improve quality of life in some patients. ${ }^{54}$ Studies (supported by the manufacturer) concluded that initiation of PPS treatment within 6 months of establishing the diagnosis of IC may be associated with greater improvement. ${ }^{55}$

3. Cyclosporine A $1.5 \mathrm{mg} / \mathrm{kg}$ twice daily was shown to be more effective than PPS but caused more adverse effects. ${ }^{56}$

4. Cimetidine $400 \mathrm{mg}$ twice daily was shown to be slightly better than placebo in a small study. ${ }^{57}$ 
5. L-arginine $500 \mathrm{mg}$ three times daily was found to show some improvement in pain and urgency in a subset of patients with bladder capacity of $800 \mathrm{~mL}$ or larger. ${ }^{58}$

6. Hydroxyzine 25 to $75 \mathrm{mg}$ at bedtime has been used alone or combined with PPS, but studies have not shown that it provides significant benefit. ${ }^{59}$

7. Prednisone, dosed at $25 \mathrm{mg}$ daily for 1 to 2 months, then tapered to the minimum required for relief of symptoms, can be used for patients with severe ulcerative IC. ${ }^{60}$

8. Muscle relaxants can be used to address the cycle of tight muscles and hypertonic muscular states of the pelvic floor. Myorelaxant drugs such as metaxolone and cyclobenzaprine generally have been shown to be beneficial for myofascial pain. Tizanidine can be beneficial for muscle spasticity and secondarily for myofascial pain. ${ }^{61}$

9. Pregabalin has been beneficial for patients with a significant myofascial pain disorder as well as neuropathic symptoms, such as burning. ${ }^{62}$

10. Montelukast $10 \mathrm{mg}$ daily, evaluated in a pilot study published in 2001 , showed some promise in the treatment of IC, but further clinical trials have yet not confirmed the initial findings. ${ }^{62}$

11. Duloxetine, a 5-HT and NA reuptake inhibitor with low activity on dopamine reuptake, showed no favorable therapeutic results in the treatment of PBS patients. ${ }^{63}$

It is important to note that $67 \%$ of 104 patients in a recent study have reported that some oral medications made their symptoms worse, including antibiotics, aspirin, ibuprofen, and decongestants. ${ }^{39}$

\section{Intravesical Medications}

A recent Cochrane review of the effectiveness of six intravesical treatments for $\mathrm{PBS} / \mathrm{IC}$ (resiniferatoxin, dimethyl sulfoxide [DMSO], Bacillus Calmette-Guerin [BCG] intravesical immunotherapy, pentosan polysulfate, oxybutynin, and alkalinization of urine $\mathrm{pH}$ ) concluded that the evidence behind the use of most intravesical preparations is limited. ${ }^{64}$

1. DMSO is a readily absorbed solvent that is a byproduct of the wood pulp industry. It is the only agent approved in the United States for intravesical treatment of IC. Its pharmacologic properties include rapid membrane penetration, enhanced drug absorption, anti-inflammatory action, analgesic action, collagen dissolution, muscle relaxation, and mast cell histamine release. It appears to desensitize nociceptive pathways in the urinary tract. Its most common adverse effect is a garliclike odor in the patient's breath. It is administered intravesically, $50 \mathrm{~mL}$ of $50 \%$ DMSO with $10 \mathrm{mg}$ of triamcinolone, 40,000 units of heparin, and $44 \mathrm{mEq}$ of sodium bicarbonate. ${ }^{3}$

2. Heparin appears to act by mimicking the activity of the bladder's own mucopolysaccharide lining and has anti-inflammatory effects. Administration of 10,000 U of heparin in sterile water, either alone or with DMSO, at varying intervals, provided good results according to observational studies. A solution of 40,000 $U$ heparin, $2 \%$ lidocaine, and $3 \mathrm{~mL} 8.4 \%$ sodium bicarbonate, administered intravesically used three times a week for 2 weeks, can provide relief of voiding symptoms, pain, and dyspareunia in patients with IC. ${ }^{65}$ The symptom relief appears to last beyond the duration of the local anesthetic activity of lidocaine, suggesting a suppression of neurologic upregulation. ${ }^{66}$

3. Alkalinized lidocaine ( $200 \mathrm{mg}$ lidocaine, alkalinized with $8.4 \%$ sodium bicarbonate solution to a final volume of $10 \mathrm{~mL}$ ), instilled intravesically five times a week in 99 women, resulted in moderate to marked improvement. ${ }^{67}$ 
4. Sodium hyaluronate (a phosphate-buffered saline solution with $40 \mathrm{mg}$ sodium hyaluronate weekly) provided $85 \%$ of patients with improvement in voiding symptoms and pain, and $55 \%$ remained with no pain or minimal bladder symptoms after therapy; $34 \%$ continued to monthly therapy. ${ }^{3}$

5. Chondroitin sulfate instilled weekly for 20 weeks, then monthly for 3 months, improved urinary symptoms.

6. Pentosan polysulfate, $300 \mathrm{mg}$ twice weekly in $50 \mathrm{~mL}$ of normal saline intravesically, has shown modest response. ${ }^{3}$

7. Intravesical BCG immunotherapy appeared promising in some studies, ${ }^{68}$ but other studies found that the benefits of BCG were minimal, or argued against routine use of BCG immunotherapy in IC patients, even if it had an acceptable safety profile. ${ }^{69,70}$

8. Resiniferatoxin, a capsaicin analog and vanilloid receptor agonist, is being considered as a new intravesical strategy for IC. Further studies are pending. ${ }^{71}$

\section{Topical Medications}

Lubricants and moisturizers (eg, Astroglide, Replens, and Femglide) can improve orgasmic function in patients with complaints of vaginal dryness and dyspareunia, without any long-term safety concerns. ${ }^{72}$ Patients who are trying to conceive should be made aware of their effect on decreasing sperm motility. ${ }^{72}$ Plain petrolatum (Vaseline) will benefit some patients. ${ }^{73}$ Topical anesthetics can be used immediately before intercourse to relieve pain. ${ }^{72,73}$ Lidocaine ointment $5 \%$ or lidocaine jelly $2 \%$ can be applied as required for symptoms and 30 minutes before sexual activity. Male sexual partners may experience penile numbness and should avoid oral contact. ${ }^{73}$ Estrogen vaginal cream can be helpful for postmenopausal women who have dyspareunia related to atrophy. ${ }^{74}$ A very small study of Zestra (a lubricating oil with herbal ingredients) showed it can improve sexual experience in women due to increasing blood flow to the genital area when applied directly to the mons pubis in patients with IC. The effects can last 45 minutes. ${ }^{75}$

\section{Herbal Therapy}

Oral herbal preparations have been used as a treatment alternative for patients with PBS. A pilot study used the herbs cornus, gardenia, curculigo, rhubarb, psoralea, and rehmannia in a tea twice a day for 6 days a week for 3 months, then once a day. Of the 25 patients studied, $61 \%$ had a significant decrease in pain at 4 weeks, and an additional $22 \%$ had a significant response at 3 months. More research is needed in this area. ${ }^{76}$

\section{Physical Therapy}

A randomized multicenter pilot trial showed benefit of manual therapy in treatment of urologic chronic pelvic pain syndrome. ${ }^{20}$ Pelvic floor manual therapy for decreasing pelvic floor hypertonicity can effectively ameliorate the symptoms of the urgency/ frequency syndrome and IC in $70 \%$ to $80 \%$ of patients. ${ }^{45}$

\section{Psychosocial Therapy}

Psychotherapy with a certified psychologist, psychiatrist, or social worker can be beneficial. Interventions aimed at increasing adaptive coping, such as guided imagery, appear to positively impact the female experience with IC. ${ }^{77}$ Relaxation techniques, diaphragmatic breathing, progressive muscle relaxation, exercise, self-visualization, and self-hypnosis have been shown to be effective in reducing stress. ${ }^{76}$ National 
support groups are also available, including the Interstitial Cystitis Association and the Interstitial Cystitis Network.

\section{Sexual Therapy}

Sexual functioning has been identified as a strong predictor of physical quality of life and as the only strong predictor of mental quality of life in patients with severe IC. ${ }^{78}$ Patients can be taught self-care strategies, such as emptying the bladder before and after sex, avoiding prolonged intercourse, minimizing pressure on the urethra, engaging in outercourse, cleansing after sexual activity, and taking pain killers or antispasmotics before engaging in sexual activity. Patients also should discuss with their partner their goals for expressing intimacy. Therapists can evaluate the patient's level of knowledge and help patients redefine normal and adequate sexual functioning with this condition. Treatment can start with nonintercourse exercises, where patients use film, erotic reading, and self-stimulation to learn what they can tolerate. Therapy can reintroduce sexual thought into patients' lives and help them feel sensual and sexual again. Sexuality in the IC patient is best managed by decreasing pain and by using a sex therapist to identify and treat desire, arousal, and orgasmic disorders. ${ }^{76}$

\section{Dietary Modifications}

Surveys have reported that dietary modifications are the fourth most common therapy patients choose. There are no controlled studies in regards to diet, but a reasonable approach is to have the patient implement a diet that for 2 or 3 months eliminates all the proposed beverages and foods that exacerbate PBS symptoms, and then add them back in one at a time. ${ }^{79}$

\section{Other Treatments}

1. Sacral neuromodulation is effective in the treatment of refractory urgency and increased frequency caused by PBS. ${ }^{80}$

2. Laser ablation of Hunner ulcers in a small study was reported to provide symptomatic relief for patients with PBS/IC previously refractory to medical treatment. The reduction in pain lasted for over a year, but half of the patients experienced relapse and had to be re-treated. ${ }^{81}$ Cystectomy with urinary diversion and bladder augmentation is considered to be a last-resort treatment option reserved for severe cases when all other approaches have failed. ${ }^{82}$

3. Local anesthetics, such as Lidocaine or Marcaine 1 to $3 \mathrm{~mL}$ without epinephrine can be injected into trigger point areas in the pelvis. Typically a series of three to five injections is used, with increasing sustained relief after each injection. ${ }^{60}$

4. Botulinum toxin type $A$ (Botox $) 80 \mathrm{U}(20 \mathrm{U} / \mathrm{mL})$ injected into puborectalis and pubococcygeus muscles under conscious sedation was no more effective than placebo in improving quality of life or reducing pain. ${ }^{83}$

5. Bladder training can extend the voiding interval by inhibiting the urge to urinate, and it has been successful in some patients. Progressive increases in the voiding interval by 15 to 30 minutes every 3 to 4 weeks can result in a decrease in frequency, nocturia, and urgency. ${ }^{76}$

\section{CARING FOR THE PATIENT WITH PBS}

Quality-of-life studies suggest that PBS patients are six times more likely than individuals in the general population to cut down on work time due to health problems, but only half as likely to do so as patients with arthritis. ${ }^{3}$ Several illnesses are associated with PBS: migraine, asthma, fibromyalgia, incontinence, chronic fatigue syndrome, 
and vulvodynia. ${ }^{84}$ The combination of any of these illnesses can be challenging to manage and control. Women with PBS report global deficits in quality of life compared with healthy controls, and they experience greater depressive symptoms. ${ }^{85}$

The quality of life of patients with PBS is affected by chronic pain, sexual dysfunction, and difficulty sleeping, and most patients need a multisystem, multidisciplinary approach. The primary care physician, as the leader of a patient-centered medical home, can offer the strongest support to patients by enlisting appropriate members of the team to aid patients in their self-management. A patient-centered team may include the primary care physician, urologist, counselor, physical therapist, pharmacist, nutritionist, social worker, and sexual therapist. The team needs to be ready to help patients who present for the management of IC flares. ${ }^{86}$

PBS is recognized as a serious medical condition associated with significant disability. Because many of the modalities used to treat this syndrome can provide only inadequate or short-term relief, continuous support of these patients is paramount. A team-based approach that can offer the patient all the modalities mentioned is necessary to decrease anxiety, depression, and recurrence of problems.

\section{REFERENCES}

1. van de Merwe J, Nordling J, Bouchelouche P, et al. Diagnostic criteria, classification, and nomenclature for painful bladder syndrome/interstitial cystitis: an ESSIC. Eur Urol 2008;53:60-7.

2. Bogart LM, Berry SH, Clemens JQ. Symptoms of interstitial cystitis, painful bladder syndrome and similar diseases in women: a systematic review. J Urol 2007;177(2):450-6.

3. Hanno PM. Painful bladder syndrome/interstitial cystitis and related disorders. In: Wein AJ, editor. Campbell-Walsh urology. 9th edition. Philadelphia: Saunders; 2007. p. 330-70.

4. Hanno PM, Landis JR, Mathews-Cook Y, et al. The diagnosis of interstitial cuystitis revisited: lessons learned from the NIH Interstitial Cistitis Database Study. J Urol 1999;161(2):553-7.

5. Sant GR, Hanno PM. Interstitial cystitis: current issues and controversies in diagnosis. Urology 2001;6(1):82-8.

6. Anderson RU, Sawyer T, Wise D, et al. Painful myofascial trigger points and pain sites in men with chronic prostatitis/chronic pelvic pain syndrome. J Urol 2009; 182(6):2753-8.

7. Warren JW, Langenberg $P$, Greenberg $P$, et al. Sites of pain from interstitial cystitis/painful bladder syndrome. J Urol 2008;180(4):1373-7.

8. Hanno PM. Interstitial cystitis - epidemiology, diagnostic criteria, clinical markers. Rev Urol 2002;4(Suppl 1):S3-8.

9. Abrams P, Baranowski A, Berger R, et al. A new classification is needed for pelvic pain syndromes - are existing terminologies of spurious diagnostic authority bad for patients? J Urol 2006;175(6):1989-90.

10. Rosenberg M, Hazzard M. Prevalence of Interstitial cystitis symptoms in women: a population based study in the primary care office. J Urol 2005;174(6):2231-4.

11. Leppilahti, Sairanen J, Tammela TL, et al, for the Finnish Interstitial Cystitis-Pelvic Pain Syndome Study Group. Prevalence of clinically confirmed interstitial cystitis in women: a population based study in Finland. J Urol 2005;174(2):407-801.

12. Clemens J, Meenan R, O'Keeffe-Rosetti M, et al. Prevalence of prostatitis-like symptoms in a managed care population. J Urol 2005;176(2):576-80. 
13. Doggweiler-Wiygul R. Urologic myofascial pain syndromes. Curr Pain Headache Rep 2004;8:445-51.

14. Warren JW, Brown V, Jacobs S, et al. Urinary tract infection and inflammation at onset of interstitial cystitis/painful bladder syndrome. Urology 2008;71(6):1085-90.

15. Al-Hadithi HN, Williams $\mathrm{H}$, Hart CA, et al. Absence of bacterial and viral DNA in bladder biopsies from patients with interstitial cystitis/chronic pelvic pain syndrome. J Urol 2005;174(1):151-4.

16. Hurst RE, Rhodes SW, Adamson PB, et al. Functional and structural characteristics of the glycosaminoglycans of the bladder luminal surface. J Urol 1987; 138(1):433-7.

17. Dupont MC, Spitsbergen JM, Kim KB, et al. Histological and neurotrophic changes triggered by varying models of bladder inflammation. J Urol 2001; 166(3):1111-8.

18. Mukerji G, Yiangou Y, Agarwal SK, et al. Transient receptor potential vanilloid receptor subtype 1 in painful bladder syndrome and its correlation with pain. J Urol 2006;176(2):797-801.

19. Ness TJ, Powell-Boone T, Cannon R, et al. Psychophysical evidence of hypersensitivity in subjects with interstitial cystitis. J Urol 2005;173(6):1983-7.

20. Fitzgerald MP, Anderson RU, Potts J, et al, for the Urological Pelvic Pain Collaborative Research Network. Randomized multicenter feasibility trial of myofascial physical therapy for the treatment of urological chronic pelvic pain syndromes. J Urol 2009;182(2):570-80.

21. Pezzone MA, Liang R, Fraser MO. A model of neural cross-talk and irritation in the pelvis: implications for the overlap of chronic pelvic pain disorders. Gastroenterology 2005;128(7):1953-64.

22. Noronha R, Akbarali $H$, Malykhina $A$, et al. Changes in urinary bladder smooth muscle function in response to colonic inflammation. Am J Physiol Renal Physiol 2007;293(5):1461-7.

23. FitzGerald MP, Brensinger C, Brubaker L, et al. What is the pain of interstitial cystitis like? Int Urogynecol J Pelvic Floor Dysfunct 2006;17(1):69-72.

24. Powell-Boone T, Ness TJ, Cannon R, et al. Menstrual cycle affects bladder pain sensation in subjects with interstitial cystitis. J Urol 2005;174(5):1832-6.

25. Kushner L, Moldwin RM. Efficiency of questionnaires used to screen for interstitial cystitis. J Urol 2006;176(2):587-92.

26. O'Leary MP, Sant GR, Fowler FJ, et al. The interstitial cystitis symptom index and problem index. Urology 1997;49(Suppl 5A):58-63.

27. Parsons CL, Dell J, Stanford EJ, et al. Increased prevalence of interstitial cystitis: previously unrecognized urologic and gynecologic cases identified using a new symptom questionnaire and intravesical potassium sensitivity. Urology 2002;60(4):573-8.

28. Litwin MS, McNaughton-Collins M, Fowler FJ Jr, et al. The National Institutes of Health chronic prostatitis symptom index: development and validation of a new outcome measure. Chronic Prostatitis Collaborative Research Network. J Urol 1999;162(2):369-75.

29. Nordling J, Anjum F, Bade J, et al. Primary evaluation of patients suspected of having interstitial cystitis (IC). Eur Urol 2004;45(5):535-682.

30. Clemens JQ, Joyce GF, Wise $M$, et al. Interstitial cystitis and painful bladder syndrome. In: Litwin MS, Saigal CS, editors. Urologic diseases in America. US Department of Health and Human Services, Public Health Service, National Institutes of Health, National Institute of Diabetes and Digestive and Kidney Diseases. Washington, DC: US Government Printing Office; 2007. p. 125-54 NIH Publication \# 07-5512. 
31. Warren JW, Howard FM, Cross RK, et al. Antecedent nonbladder syndromes in case-control study of interstitial cystitis/painful bladder syndrome. Urology 2009;73(1):52-7.

32. Peters KM, Kalinowski SE, Carrico DJ, et al. Fact or fiction-is abuse prevalent in patients with interstitial cystitis? Results from a community survey and clinic population. J Urol 2007;178(3 Pt 1):891-5.

33. Dimitrakov J, Guthrie D. Genetics and phenotyping of urological chronic pelvic pain syndrome. J Urol 2009;181(4):1550-7.

34. Gardella B, Porru D, Ferdeghini F, et al. Insight into urogynecologic features of women with interstitial cystitis/painful bladder syndrome. Eur Urol 2008;54(5): 1145-51.

35. Peters KM, Carrico DJ, Diokno AC. Characterization of a clinical cohort of 87 women with interstitial cystitis/painful bladder syndrome. Urology 2008;71(4):634-40.

36. Kahn BS, Tatro C, Parsons CL, et al. Prevalence of interstitial cystitis in vulvodynia patients detected by bladder potassium sensitivity. J Sex Med 2010;7: 996-1002.

37. Ohl L. Essentials of female sexual dysfunction from a sex therapy perspective. Urol Nurs 2007;27(1):57-63.

38. Goldstein I. Urologic management of women with sexual health concerns. In: Wein AJ, editor. Wein: Campbell-Walsh urology. Philadelphia: Saunders; 2007. Chapter 28.

39. Shorter B, Lesser M, Moldwin RM, et al. Effect of comestibles on symptoms of interstitial cystitis. J Urol 2007;178(1):145-52.

40. Nickel JC, Tripp DA, Pontari M, et al. Psychosocial phenotyping in women with interstitial cystitis/painful bladder syndrome: a case-control study. J Urol 2010; 183(1):167-72.

41. Nickel JC, Payne CK, Forrest J, et al. The relationship among symptoms, sleep disturbances and quality of life in patients with interstitial cystitis. J Urol 2009; 181(6):2555-61.

42. Shoskes DA, Nickel JC, Rackley RR, et al. Clinical phenotyping in chronic prostatitis/chronic pelvic pain syndrome: a phenotypic classification of UCPPS. Prostate Cancer Prostatic Dis 2009;12:177-83.

43. Kroenke K, Spitzer RL, Williams JB. The PHQ-9: validity of a brief depression severity measure. J Gen Intern Med 2001;16(9):606-13.

44. Sullivan MJL, Bishop S, Pivik J, et al. The pain catastrophizing scale: development and validation. Psychol Assess 1995;7(4):524-32.

45. Weiss JM. Pelvic floor myofascial trigger points: manual therapy for interstitial cystitis and the urgency-frequency syndrome. J Urol 2001;166(6):2226-31.

46. Irwin P, Samsudin A. Reinvestigation of patients with a diagnosis of interstitial cystitis: common things are sometimes common. J Urol 2005;174(2): 584-7.

47. Neal DE. Interstitial cystitis: evaluation and related conditions. J Urol 2009;181(6): 2414-5.

48. Tissot WD, Diokno AC, Peters KM. A referral center's experience with transitional cell carcinoma misdiagnosed as interstitial cystitis. J Urol 2004;172(2): 478-80.

49. Wein A. Primary evaluation of patients suspected of having interstitial cystitis (IC). J Urol 2004;172(6):2494-5.

50. Kim SH, Kim TB, Kim SW, et al. Urodynamic findings of the painful bladder syndrome/interstitial cystitis: a comparison with idiopathic overactive bladder. J Urol 2009;181(6):2550-4. 
51. Parsons CL, Bullen M, Kahn BS, et al. Gynecologic presentation of interstitial cystitis as detected by intravesical potassium sensitivity. Obstet Gynecol 2001; 98(1):127-32.

52. van Ophoven A, Hertle L. Long term results of amitripyline treatment for interstitial cystitis. J Urol 2005;174(5):1837-40.

53. van Ophoven A, Pokupic S, Heinecke A, et al. A prospective, randomized, placebo controlled, double-blind study of amitriptyline for the treatment of interstitial cystitis. J Urol 2004;172(2):533-6.

54. Nickel JC, Barkin J, Forrest J, et al, for the Elmiron Study Group. Randomized, double-blind, dose-ranging study of pentosan polysulfate sodium for interstitial cystitis. Urology 2005;65(4):654-8.

55. Nickel JC, Kaufman DM, Zhang HF, et al. Time to initiation of pentosan polysulfate sodium treatment after interstitial cystitis diagnosis: effect on symptom improvement. Urology 2008;71(1):57-61.

56. Sairanen J, Tammela TL, Leppilahti M, et al. Cyclosporine A and pentosan polysulfate sodium for the treatment of interstitial cystitis: a randomized comparative study. J Urol 2005;174(6):2235-8.

57. Thilagarajah R, Witherow RO, Walker MM. Oral cimetidine gives effective symptom relief in painful bladder disease: a prospective, randomized, doubleblind placebo-controlled trial. BJU Int 2001;87(3):207-12.

58. Korting GE, Smith SD, Wheeler MA, et al. A randomized double-blind trial of oral L-arginine for treatment of interstitial cystitis. J Urol 1999;161(2):558-65.

59. Sant GR, Propert KJ, Hanno PM, et al. A pilot clinical trial of oral pentosan polysulfate and oral hydroxyzine in patients with interstitial cystitis. The Interstitial Cystitis Clinical Trials Group. J Urol 2003;170(3):810-5.

60. Soucy F, Grégoire M. Efficacy of prednisone for severe refractory ulcerative interstitial cystitis. J Urol 2005;173(3):841-3.

61. Butrick CW. Pelvic floor hypertonic disorders: identification and management. Obstet Gynecol Clin North Am 2009;36(3):707-22.

62. Bouchelouche K, Nordling J, Hald T, et al. The cysteinyl leukotriene D4 receptor antagonist montelukast for the treatment of interstitial cystitis. J Urol 2001;166(5):1734-7.

63. van Ophoven A, Hertle L. The dual serotonin and noradrenaline reuptake inhibitor duloxetine for the treatment of interstitial cystitis: results of an observational study. J Urol 2007; 177(2):552-5.

64. Dawson TE, Jamison J. Intravesical treatments for painful bladder syndrome/ interstitial cystitis. Cochrane Database Syst Rev 2007;4:CD006113.

65. Welk BK, Teichman JM. Dyspareunia response in patients with interstitial cystitis treated with intravesical lidocaine, bicarbonate, and heparin. Urology 2008;71(1): 67-70.

66. Parsons CL. Successful down-regulation of bladder sensory nerves with combination of heparin and alkalinized lidocaine in patients with interstitial cystitis. Urology 2005;65(1):45-8.

67. Nickel JC, Moldwin R, Lee S, et al. Intravesical alkalinized lidocaine (PSD597) offers sustained relief from symptoms of interstitial cystitis and painful bladder syndrome. BJU Int 2009;103(7):910-8.

68. Mayer R, Propert KJ, Peters KM, et al. A randomized controlled trial of intravesical bacillus Calmette-Guerin for treatment refractory interstitial cystitis. The Interstitial cystitis CLinical trials Group. J Urol 2005;173:1186-91.

69. Propert KJ, Mayer R, Nickel JC, et al. Follow-up of patients with interstitial cystitis responsive to treatment with intravesical bacillus calmette-guerin or placebo. J Urol 2008;179. 
70. Mayer R, Propert KJ, Peters KM, et al. A randomized controlled trial of intravesical bacillus calmette-guerin for treatment refractory interstitial cystitis. J Urol 2005; 173(4):1186-91.

71. Lazzeri M, Beneforti P, Spinelli M, et al. Intravesical resiniferatoxin for the treatment of hypersensitive disorder: a randomized placebo controlled study. J Urol 2000;164(3 Pt 1):676-9.

72. Anderson L, Lewis SE, McClure N. The effects of coital lubricants on sperm motility in vitro. Hum Reprod 1998;13:3351-6.

73. Haefner HK, Collins ME, Davis GD, et al. The vulvodynia guideline. J Low Genit Tract Dis 2005;9(1):40-51.

74. Clayton A, Hamilton D. Female sexual dysfunction. Psychiatr Clin North Am 2010; 33(2):323-38.

75. Ferguson DM, Steidle CP, Singh GS, et al. Randomized, placebo-controlled, double-blind, crossover design trial of the efficacy and safety of "Zestra for Women" in women with and without female sexual arousal disorder. J Sex Marital Ther 2003;29(Suppl 1):33-44.

76. Whitmore KE. Complementary and alternative therapies as treatment approaches for interstitial cystitis. Rev Urol 2002;4(Suppl 1):S28-35.

77. Rothrock NE, Lutgendorf SK, Kreder KJ. Coping strategies in patients with interstitial cystitis: relationships with quality of life and depression. J Urol 2003;169(1): 233-6.

78. Nickel JC, Tripp D, Teal V, et al, for the Interstitial Cystitis Collaborative Trials Group. Sexual function is a determinant of poor quality of life for women with treatment refractory interstitial cystitis. J Urol 2007;177(5):1832-6.

79. Rovner E, Propert KJ, Brensinger C, et al. Treatments used in women with interstitial cystitis: the interstitial cystitis data base (ICDB) study experience. The Interstitial Cystitis Data Base Study Group. Urology 2000;56(6):940-5.

80. Powell CR, Kreder KJ. Long-term outcomes of urgency-frequency syndrome due to painful bladder syndrome treated with sacral neuromodulation and analysis of failures. J Urol 2010;183(1):173-6.

81. Rofeim O, Hom D, Freid RM, et al. Use of the neodymium: YAG laser for interstitial cystitis: a prospective study. J Urol 2001;166(1):134-6.

82. Webster DC, Brennan T. Interstitial cystitis. Arch Gynecol Obstet 2007;275(4): 223-9.

83. Abbott JA, Jarvis SK, Lyons SD, et al. Botulinum toxin type A for chronic pain and pelvic floor spasm in women: a randomized controlled trial. Obstet Gynecol 2006; 108(4):915-23.

84. Marinkovic SP, Moldwin R, Gillen LM, et al. The management of interstitial cystitis or painful bladder syndrome in women. BMJ 2009;339:b2707.

85. Rothrock NE, Lutgendorf SK, Hoffman A, et al. Depressive symptoms and quality of life in patients with interstitial cystitis. J Urol 2002;167(4):1763-7.

86. Forrest JB, Dell JR. Successful management of interstitial cystitis in clinical practice. Urology 2007;69(Suppl 4):82-6. 